\title{
Searching the Light: Experiences of Visually-Impaired Students Attending Mainstream School
}

\author{
Denmark L. Yonson \\ Philippine Normal University, Visayas, Philippines
}

\begin{abstract}
Being a visually-impaired (VI) student attending mainstream classes poses a challenge to them considering the limitation presented by their limited vision. This phenomenological study tried to explore these difficulties and identify the different coping skills that helped them in pursuing their schooling. It was found out that VI students developed a certain adaptive mechanism that enables them to survive their academic journey. Their difficulty taught them to innovate themselves to become accustomed to the growing demand of society for them to be equally competitive and productive individual that does not consider their difficulties as hindrance. It was found out that VI students who are in the mainstream classes have a stronger socio-academic adaptability which enables them to relate themselves to their mainstream counterparts and to excel in their academics. The study revealed that their social adaptation involves strong spiritual foundation, self-confidence, self-motivation, sense of belongingness, and better support system from families and friends. On the other hand, their academic adaptation includes technology, effective teacher aides, innovative strategies, and materials for the blind. When all this components are considered, there is an assurance that VI students attending mainstream classes can finish their schooling.
\end{abstract}

Keywords: education, inclusive education, lived experiences, VI students, Philippines

\section{Introduction}

Being visually-impaired (VI) had been considered as a difficulty. It will not enable you to see the colors and beauty around you and it feels like living in the dark side of the world. It was then believed that if a person is VI, he/she may not be able to perform the things that typical people do and will not see what they usually see. Blindness hinders them from moving around, crossing the street, taking a walk, and riding a bus. It deters their capacity to read texts in usual books. They do not see how movies are made and how actors and actresses act, thus making them quite different from the others. This becomes a factor that holds them back from going to school. Hence, being VI was treated as a disorder that hinders success.

But that was a long time ago. When being VI was thought to be a difficulty that could not be remedied. Recently though, VI people were seen to be at par with the common populace. They can cross the streets, they can do the household chores, they can do extraordinary jobs, they can email, and most of all, they go to school. Since then, the view of the world towards the VI people changed greatly and positively.

For a while, it was thought that VI people should have a special school for them that would cater their needs. Basically, their absence of sight requires them to have special type of teaching pedagogy, a quite

Denmark L. Yonson, Ph.D. in Mathematics Education, Instructor III, Faculty of Teacher Development, Philippine Normal University. 
different type of treatment from the others. But potentials were seen in them and they had proven themselves that they could be and they should be treated equally like us.

The community had responded positively to the belief that VI student may be impaired visually, but are normal like us, and thus, should be treated fairly. Schools had become more welcoming and tried to develop programs that accepts their differences and treats them as normal ones. Hence, they were allowed to enroll in a regular class. In addition, one of the major thrusts of the Education of All Handicapped Children Act P. L. 94-142, is the requirement that handicapped students, to the most possible extent be educated with children who are not handicapped (Hatlen \& Curry, 1988).

Attending the regular class becomes a new trade for the VI students. They develop ways of adapting to their new environment. They come in contact and establish relationships with regular students and academically compete with them at the same time. Sacks and Wolffe (2006) cited social competence as critical for success in the community and might as well in education. But how do they actually adapt to this new environment, how do they study their lessons, how do they participate in classroom discussion, how do they relate with their classmates, and how are they treated by them are some good questions to ask to determine the holistic development of VI people in the academe. Thus, this study is conducted.

\section{The Statement of the Problem}

The purpose of this phenomenological study is to discover the difficulty encountered by the selected college students who are VI of Philippine Normal University, Visayas.

Specifically, the study seeks to answer the following key questions:

1. What are the difficulties encountered by the VI students?

2. How do VI students cope with their difficulties encountered in attending regular classes?

3. How do their experiences change their views about attending school?

\section{Literature on Inclusive Education}

Every individual deserves to be educated. Anyone who wants to study and learn reseraves the right to choose where he/she wants to pursue his/her education. Schools were supposed to accept all types of students into their mainstream education. Unfortunately, not all of them had welcomed this idea especially to persons who are differently-abled not until the introduction of inclusion model of education. Jordan (2015) defined inclusion model in the educational setting as a method of teaching and learning where students with learning difficulties and disabilities are encouraged to be with the mainstream class. Under this model, differently-able students (e.g., VI students) are catered and receive the same education that regular students enjoy. In the same manner, these differently-abled persons receive special educational needs to help them succeed in the academic setting. These supports are personalized towards the student to meet their specific needs and may include other mechanisms, such as extended instruction, one-on-one sessions, counseling, as well as inside and outside the classroom interactions and accommodations. These specialized accommodations are tailored based on the kind of disabilities the students possess which might be classified into intellectual and physical disabilities. Though these differently-abled students vary in disabilities they possess, they share common experiences. All children identified with a disability in the educational setting are considered to have significant impairment emotionally, intellectually, or physically that requires them to be provided with extra resources and assistance to achieve in the academic setting.

An authority who promotes inclusion model believes that there should be no distinction between the 
schools or classrooms for students with disabilities from students who have no disabilities. At present, there is still a growing debate on what type of school setting is best and developmentally appropriate to students with special needs though there are schools, both state and private, that offer education to students with disabilities separate from non-disabled students. Batu, Bilgin, Oksal, and Sadioglu (2013) reported that a number of studies have found a negative attitudes towards inclusion, partly because teachers who taught them are not trained and prepared to do so. While it is acceptable that differently-abled students can be part of the mainstream classroom, these students with disabilities require extra assistance. In the inclusion model, this concern is addressed through the provision of assistance provided for children while they continue to mainstream with children in regular classrooms based on their needs.

Inclusion model provides equal opportunities for students with special needs to participate fully and experience the class catered for regular students. Unfortunately, studies have shown that for some students with special needs, placement in regular education classrooms without appropriate social supports has resulted in social isolation, and ultimately, a more restrictive environment (Gresham, 1981; Sacks et al., 1992, as cited in Celeste \& Grum, 2010). Hence, it was strongly suggested that classroom teachers need to make the development of social competence a priority for children with special needs. Efforts to include students with special needs are most effective when teachers are actively involved in assessing the students and helping them acquire appropriate social skills. It is critical for children who are visually impaired to be taught the social skills that are necessary to interact effectively with their peers. It is also important that the children's ability to implement these skills successfully is carefully monitored (Kekelis \& Sacks, 1988; Sacks et al., 1992, as cited in Celeste \& Grum, 2010).

Being VI is a challenge that everyone who has it has to overcome. Their lack of vision is undeniably hinders them from doing things. One of these things is attending school. Even more challenging is integrating them in a classroom of which their classmates are mainstream students. The VI students endowed upon them the responsibility to survive and succeed among these mainstream students despite of their disability. The skills and tools of blindness are the key to being able to function competitively without frustration and with success. Most sighted people believe that blind people need a lot of help. People have even seen the so-called "sensitivity exercises", designed to develop awareness and understanding of blindness, which have as their explicit goal, "the understanding of what it is like to be helpless". The lack of sight makes the individual aloof from the physical world. This sensory, social, and physical isolation creates anxiety and adjustment problems in the personality of blind subjects in the society (Mishra \& Singh, 2012). These limitations created a sense of challenge to the VI students. With these challenges posed to them as students, these VI students developed among them, a coping mechanism that tries to address the challenges they are facing. These coping mechanisms might succeed, however, some may not. It is therefore imperative to note how this kind of learners adapt to the challenges they face especially that they are in the mainstream class. In the same manner, it is important to consider the difficulties they encounter given the kind of class they have.

The study will not only venture on the academic engagement of the students rather it will probe their social adaptation and interaction with the regular students and how these interactions affect them. Learning from their experiences, the result of the research might provide a strategy that will be helpful in the development of VI friendly classroom and would suggest ways to help the VI students become more at ease with the situation they have and the kind of classroom environment they are into. The data that they will be putting into the research might pave the way to a better learning environment that would boost them 
holistically.

The schematic diagram below shows how the data extracted from this study shall be used to develop an insight that shows how the VI students adapts to the academic and social interaction demands in attending mainstream classes. The model is cyclic in nature. It shows that the lived experiences of VI students come across different difficulties that challenge their academic and social soundness. Because of these challenges, VI students tend to develop a coping mechanism to address or overcome the difficulties that had been encountered. As a result, VI students develop a behavior that adapts to certain challenges in their daily life as a student. The kind of adaptation that they developed is termed as socio-academic adaptation. This refers to the coping ability of VI students when faced with a certain difficulty that challenges their capability as a person with disability. Their adaptive behavior predicts their success in continuing their academic journey. When this socio-academic adaptability of the VI students stabilize, when the same challenges comes their way, they already know what to do since they had already established a coping mechanism that would deal with the issue. And so, the cycle goes on but VI students become equipped with necessary coping skills whenever it is necessary.

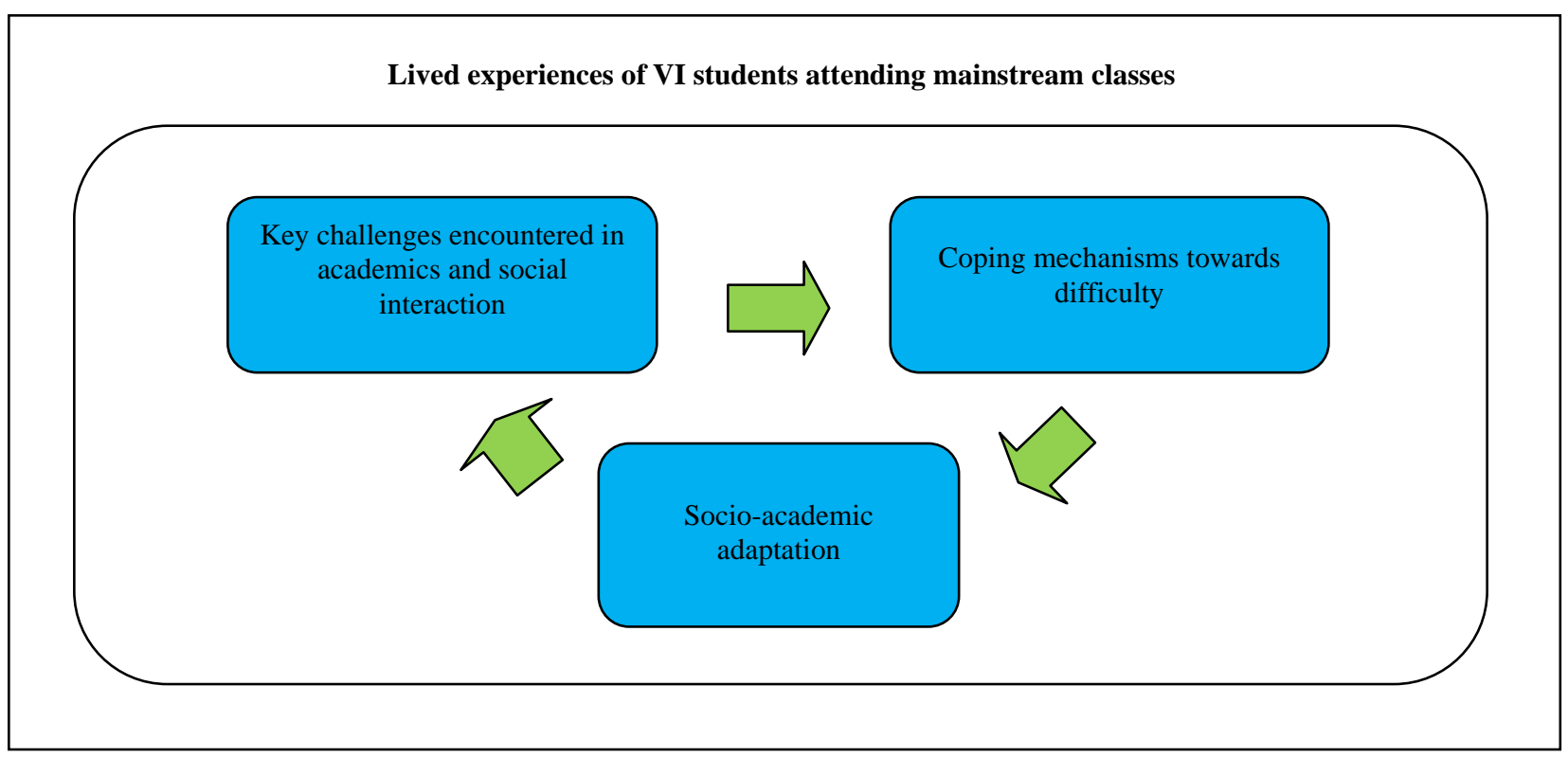

Figure 1. A schematic diagram showing the conceptual framework of the study.

\section{Scope and Limitation}

The respondents of the study will be the VI college students of Philippine Normal University, Visayas, who are officially enrolled for the academic year 2015-2016.

The data will be analyzed based on the responses of the respondents to the various items questions from the interview.

The findings of this study will be viewed from the standpoint of the formulated research problem, procedure in data collection, and coding technique employed in the analysis of the data.

\section{Methodology}

This chapter presents the research design used in the study. It also presents the participants of the study, the role of the researcher, the data collection procedure of the study, the manner of analyzing the data retrieved from the interviews and observations, and the validity and reliability of the data collection instrument. 


\section{Research Design}

Qualitative research is grounded in a philosophical position which is broadly "interpretivist" in the sense that it is concerned with how the social world is interpreted, understood, experienced, produced, or constituted (Mason, 2002).

To meet the objective of the study, a phenomenological research design is considered the most appropriate. Phenomenological in the sense, that the researcher described the lived experience of participants about their experiences as they go along with their academic journey.

\section{Participants of the Study}

Miles and Huberman (1994, as cited in Creswell, 2014) stressed that the discussion about the participants and site might include four aspects, such as the setting where the research will take place, the actors which refers to the participants who will be observed or interviewed, the events which will focus on what will be observed or interviewed from the actors, and the process which refers to the evolving nature of events undertaken by the actors within the setting.

The participants of the study are the two VI students who are currently enrolled at Philippine Normal University, Visayas. The researcher employed purposive sampling for a fact that the current study deals with a specific phenomenon that does not apply to the general population. One of the respondents is a fourth-year college student who is about to graduate, thus, the participant is assumed to have a rich experience being in the classroom with mainstream students. On the other hand, the other respondent is a sophomore student and is assumed to be adjusting to the situation where the classroom is full with mainstream students. With the gap in years between the two respondents, the researcher could retrieve data that probe how the VI student adjust and had adjusted their selves to adapt to the demands of learning with the mainstream students. Though Creswell (2014) suggested that sample size for a phenomenology study should at least range from three to 10, the researcher still employ the phenomenology with only two respondents due to the fact that they are only currently enrolled VI students.

Table 1

Participants of the Study

\begin{tabular}{llll}
\hline Name & Sex & Age & Year level \\
\hline${ }^{*}$ John & Male & 23 & 4 th Year \\
${ }^{*}$ Faith & Female & 18 & 2nd Year \\
\hline
\end{tabular}

Note. ${ }^{*}$ not their real names.

\section{Setting of the Study}

Qualitative study tends to collect data in the field at the site where participants experience the issue or problem under study (Creswell, 2013; Hatch, 2002; Marshall \& Rossman, 2011). The study was conducted to the students of Philippine Normal University, Visayas. Philippine Normal University, Visayas is a teacher education institution specializing in producing elementary and secondary teachers. It is strategically located at Boy Albert Street, Barangay Zone I, Cadiz City.

\section{Research Instrument}

The researcher-made instrument was used in the conduct of this qualitative study. To assure its validity and reliability, it had undergone the necessary validity test which was done by competent evaluators in the field 
of education. The instrument was composed of two parts namely: the personal data of the participant and the interview proper. The personal data deal with the basic information of the respondents and the interview proper was composed of a series of questions that tries to answer the statement of the problem this research aimed to answer. It is composed of open-ended questions which allow the flow of ideas of the participants.

\section{Validity}

Validity in qualitative research means that the researcher checks for the accuracy of the findings by employing certain procedures. Validity is one of the strengths of qualitative research and is based in determining whether the findings are accurate from the standpoint of the researcher, the participant, or the readers of an account (Creswell \& Miller, 2000). In this study, the researcher employed triangulation of data though the data shall only be limited to the interview and observations but the researcher believes that these two sources of data can validate each other's truthfulness, authenticity, and credibility (Creswell \& Miller, 2000). Member checking was also be used to determine the accuracy of the qualitative findings through taking the final report or specific descriptions or themes back to participants and determining whether these participants feel that they are accurate. This process involves conducting a follow-up interview with participants in the study and providing an opportunity for them to comment on the findings.

\section{Reliability}

Reliability on the other hand, indicates that the researcher's approach is consistent across different researchers and projects (Gibbs, 2007). To assure the reliability of the findings of the study, the researcher checks transcripts to make sure that they do not contain obvious mistakes made during transcription. The researcher applied the intercoder agreement by finding another person who can cross check for the codes. That is, the coders must at least agree on codes used for the same passages in the text.

\section{Data Collection Procedure}

The researcher sought an approval from the dean of the academics through the associate dean, where the research will be conducted. A letter of permission was made and duly noted by the research dean of the school. When the approval is already sought, the researcher set a series of interview which commenced at the end of February and culminated on March 2016. Two interview sessions and one observation for each participant was performed by the researcher. The second interview was performed to validate the truthfulness of the first interview, thus the same set of questions shall be asked from the participants.

A qualitative interview was employed in doing the research. The researcher conducted face-to-face interviews with the participants. These interviews involved unstructured and generally open-ended questions that are few in number and intended to elicit views and opinions from the participant (Creswell, 2014). To strengthen the observation data recorded by the researcher, a qualitative observation was performed. Creswell (2014) referred to qualitative observation as the researcher took filed notes on the behavior and activities of individuals at the research site. The researcher records, in an unstructured or semi-structured way, the activities at the research site.

The researcher followed an interview protocol in asking questions and recording answers during the interview. The researcher developed a log to keep a record of the interview aside from the video- or audiorecording. 


\section{Data Analysis Procedures}

The data gathered from the interview and observation had undergone segmenting and taking apart of necessary and relevant data. Because the text in the interview and observation might be dense and rich, in the analysis of data, the researcher winnowed the data (Guest, Mac Queen, \& Namey, 2012, as cited in Creswell, 2014). It is a process of focusing in on some data and disregarding other parts of it. The impact of this process is to aggregate data into small number of themes (Creswell, 2013). The researcher encoded the data gathered and generated some themes. Phenomenological research uses the analysis of significant statements, the generation of meaning units and development of what Moustakas (1994) called an essence description. The researcher organized and prepared the data for analysis. This involved transcribing interviews, typing up field notes, sorting, and arranging the data into different types. After looking at the data, coding started. Coding is the process of organizing the data by bracketing texts and writing a word representing a category (Rossman \& Rallis, 2012). It involves taking text data or pictures gathered during data collection, segmenting sentences (or paragraphs) into categories and labeling those categories with a term. The researcher developed codes that emerge during the data analysis (Creswell, 2013). The coding process was then used to generate a description which involves a detailed rendering of information about people, places, or events in a setting (Creswell, 2014). The codes developed were represented in a qualitative narrative to convey the findings of the analysis and to finally develop a singular idea that covers all the themes that had emerged and to be considered as the final eidetic insight.

The schematic diagram on the next page shows the data analysis procedure discussed above until the final eidetic insight is deduced from the findings.

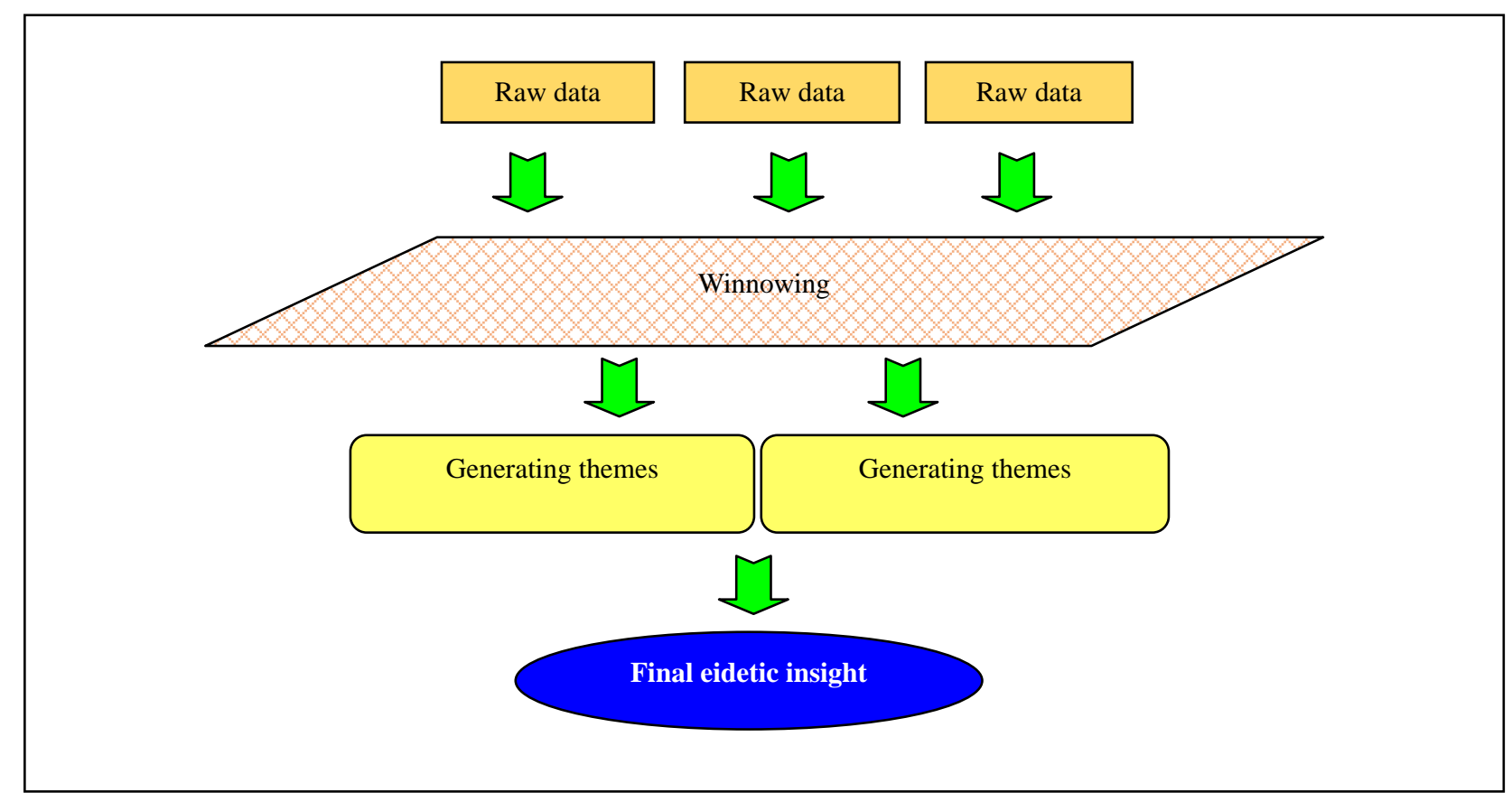

Figure 2. Schematic diagram showing the data analysis procedure. 


\section{Results and Discussion}

\section{Problem 1: What Are the Difficulties Encountered by the VI Students?}

Being VI is not easy. There are many difficulties that one should overcome. As one of the participants narrates, from the moment a VI wakes up until he/she reached the school, there are difficulties he/she encountered especially in mobility. Not to mention the difficulties of not seeing what is being discussed or written on the board and would only depend largely on what his/her ear can hear and what much his/her hands can copy. In addition, students like them were likewise bullied because of their disabilities to the extent that people around them tried to bring down their personality and ruin their self-esteem. Thus, their academic journey becomes difficult for them if they are not physically and emotionally ready to take on the journey.

In addition, losing self-confidence is one of the most influential factors that may sometimes hold back students with disabilities to go to school and even attend a class together with mainstream students. It is a difficulty that is difficult to cope with since it directly affects your emotion and attacks your personality. Worst, when it negatively affects oneself and he/she feels pity of herself/himself of the disability one has. Another difficulty that the participant sighted was dealing with subjects, especially mathematics. Since their vision becomes a limiting factor for their engagement in class, at times a certain lesson for them becomes too difficult especially when it comes to drawing like making graphs and the likes. When not properly addressed, these difficulties would create a negative feeling among the VI that would discourage them from attending school.

\section{Problem 2: How Do VI Students Cope With Their Difficulties Encountered in Attending Regular Classes?}

Learning to overcome a difficulty is a challenge that every VI needs to overcome. According to the participant, to overcome such difficulty, one need to know his/her roots and where one's life is rooted. Believe in God and in his/her plans becomes his/her inspiration in fighting against the challenges that his/her disability has to offer. In terms of overcoming his/her academic difficulty, innovation becomes his/her powerful technique. When he thinks he/she cannot do the activities demanded by his/her academic subjects due to his/her difficulty, he/she tries to communicate with his/her teachers and try to think of other projects that might be different but that at least the same competency can be measured.

On the other hand, materials and technology for the blind were very helpful in overcoming the difficulty posed by not being able to see. As the participant shares, development of materials for the blind would help them ease their challenges coupled with determination and focus to make work things out.

\section{Problem 3: How Do Their Experiences Change Their Views About Attending School?}

Education for persons with disabilities (PWD) before was quite difficult and challenging for both the teachers and the VI students. However, with the advent of technology, teaching VI becomes easy and comfortable. As the participant quoted, technology becomes an essential tool for their effective learning and with the help of this. And they can become more competitive and equally equipped with their mainstream counterparts. Technology becomes an important tool for education and will become an important medium for a successful implementation of education to all not only to the PWDs. Disability is not a hindrance to anybody's education. It is the gateway which everyone should pass to succeed in life.

\section{Paving the Way: Making Every School VI Ready}

Teaching in a mainstream class is quite different from teaching students with disabilities. Much more 
having students with disabilities in a class of mainstream students. A teacher in that kind of classroom should be equipped with necessary training, so that the kind of pedagogy that they employ in delivering their lesson should cater not only to the mainstream student, but likewise to the students with disabilities specifically VI students. Teachers are the individuals who work directly with the students and understanding how they perceive the practice of inclusion is an important step in bringing about effective inclusionary practices in the schools (Costley, 2013). Unfortunately, the findings of the study show that most schools where the participants intend to study do not have the necessary preparation that would cater to students like them. Education should be for all. To address this awareness, schools and universities should be ready to accept all kinds of learner.

Certain factors should be considered to make a certain school or university ready. First and foremost, schools should have facilities that address the needs of varied learners having certain disabilities. An individual's perception, opinions, ways of construing systems, intentions, and attitudes influence the successful implementation of a program. Therefore, it is recommended that schools receive training on implementing inclusion practices (Costley, 2013). Second, a well-planned curriculum should be developed which considers students with disabilities. Third, teachers should be trained in mentoring students who are VI. They should also develop the kind of pedagogy that adapts to the needs of the VI like Braille, computer-aided instructions for the blind and technology-based approaches that encourage learning among VI students. They should likewise be oriented on how to deal with VI students inside the classroom, considering the ethical aspects in communicating and establishing relations with them. According to a Porter and Lacey's (2008) British study, it appears that even in specialized schools. Few teachers have specific qualifications for teaching students with VI, and consequently, do not necessarily thoroughly understand how visual impairment can affect learning access. If this is the case, it would be important to note how teachers should prepare to teach VI students.

\section{$3 S$ in Success: Self-motivation, Self-confidence, and Self-esteem}

The disabilities of VI students had most of the time become the ultimate factors that deprives them of having self-confidence. The feeling that they are different and that something is missing in them brings down their self-esteem. Not to mention the teases that they might hear from their mainstream counterparts. VI students should develop mechanisms to overcome their low self-esteem through discovering and strengthening the potentials that they have. Moreover, appreciation of the things they are capable of doing would uplift their spirit and will keep them going. Likewise, giving them opportunities to express themselves without minding their difficulties will surely develop their self-confidence and self-motivation that will eventually boost their self-esteem and will inspire them to continue their academic journey. In this study, one of the participants has a strong self-confidence and self-motivation that made him copes with all the difficulties he encountered in his journey. According to him, people will try to drag him down but if students like him have a strong foundation of confidence and self-esteem, none can bring them down.

\section{Sense of Belongingness: Making the Class VI Friendly}

Students who are VI experience difficulty most especially in participating to school activities that involve mobility and dealing with other classmates like in group works and performances. The participants of the study had shown confidence in participating with activities, because they feel that their mainstream classmates welcome them and accepted their disability and did not let them feel that they are different from them. In a study made by Bennett and Gallagher (2013), students with a disability were significantly more positive about their opportunities to socialize and form friendships than were their teachers, educational assistants, employers, 
and peers. It is therefore important that they should be offered an environment that welcomes their friendliness and socialization. In this sense, it can be said that having a class that possesses an environment that promotes sense of belonging to the VI students encourages them to participate actively in class activities. Negative attitudes and ineffective attempts at social inclusion are often the result of a lack of teaching of value and appreciation for diversity (Lindsay \& McPherson, 2012). VI students feel that they are normal when the people around them let them feel that they are indeed normal. If VI students feel that they are like normal students having no disabilities, dynamic participation from them could be expected. Jordan (2015) revealed that VI students demonstrated a positive attitude towards their school integration, consider themselves integrated in their group and are accepted by their classmates in all activities involving the educational environment.

\section{Empowered VI Aides: Building Stronger Backbones for VIs}

The limited visions of VI students hinder them from seeing their surroundings and especially the texts written on the board. This becomes a difficulty that VI students should overcome, but they could not without the assistance of others. This is where the role of VI Aides comes along. They become the support system of the VI students that resolves their difficulty in coping with their lack of sight. They become the eyes of the VI students. The importance of these aides is empirical to consider, because they directly affect the performance of VI students. Deducing from the experience of the participants, their helper or aides are the ones copying for them, dictating to them and even writing the lessons. Thus, it is important that they should be trained and knowledgeable enough at what they are doing especially in the academic aspect. Kamenopoulou (2012) shared that learning support assistants, whose role is to remove barriers to communication, emerged as a hindrance to interactions. The very reason that they should at least be literate or even taking education courses, so that they will know what to do, they know what they are doing, and they can teach the VI students effectively. There should be an agency that trains VI Aides since if VI Aides are well-trained, there is a possibility that the ones they are assisting could become competitive since they can give additional knowledge on a certain lesson.

\section{Technology and Training: Bridging the Gap for Successful VI Learning}

Technology becomes an indispensable partner of VI students. This becomes their strongest ally to compete with the mainstream students and to adapt to the growing demand for competitive students with or without disability. Certain technologies had already been developed that had been proven effective to assist VI students. These become their virtual teacher that provides them with additional skills necessary for them to survive the mainstream classes and help them in presentations, reports, and projects. This technology should be made available to VI students to maximize their potential of becoming a better student comparable to their mainstream counterparts. Students with visual disabilities must have assistive technologies that facilitate curriculum access. Curriculum access can be addressed effectively and efficiently by assuring that students have the appropriate tools: Screen readers, screen magnification software, braille printers, personal digital assistants (PDAs) with and without braille displays, and global positioning enhancements. But these tools are often expensive, and the expense cannot be distributed among several students, because they are adapted to meet an individual's needs. It was said that the most challenging part of designing technology is to give the new technology to those who need the most (Shapiro, 1993). Equally as hard, however, may be what Rathbun and West (2003) stressed between the difference of those people who have known the operations in the computer and have skills in accessing them and those who do not. 


\section{Strengthening the Spiritual Bond and Support System From Family to Friends}

Being VI makes one different from others. Past research suggests that up to $50 \%$ of children with disabilities feel that they do not belong within their class, are often lonely, isolated, and do not feel safe (Tavares, 2011). Being different at times brings you down lowering your self-esteem and may lead to depression. Thus, it is important that there should be people that would encourage these students to keep going and making them believe that they are equally competent and that there support is unfading. This support can be found from their parents and friends. Parents and other people surrounding VI students should provide an environment that encourages them and never letting them feel they have something that normal people do. It is important that they will be guided and educated that just like other normal people they can live their life normally and that they can do things far better than other normal people can. Equally, important is strengthening the spiritual aspect of the VI students. According to the participants, who believing that God is always on his side made him go forward and never quit. It is good to have organizations that welcome VI students and help them go along with their lives introducing them to God and making them believe that with God's help they can conquer their difficulties.

\section{Enduring Education: Inspiring Others}

Finishing a degree despite of difficulty is not a mission impossible. This was proven by the participants. According to them, the motivation to keep going and inspire others having a difficulty like them make them continue the journey of getting a degree. They believe that if VI students shall instill themselves that they can overcome whatever difficulty that will come their way, indeed they can overcome it and come out successful.

\section{Conclusions}

VI students experience different kinds of difficulties, such as mobility, social adjustments, coping up with lessons, and even bullying. They become prone to physical hazards due to their limited visions. There opportunities in education were likewise limited considering their limitations. But most of all, they are prone to self-pity and lower self-esteem as a result of their disabilities. They can become more sensitive and eventually loss their motivation to go to school. On the other hand, VI students, being aware of their difficulty had developed their own mechanisms of overcoming their weaknesses and turned it into strength. They innovate and discover ideas and ways that could improve their self. They welcome the advent of technology in their lives as a powerful tool in expressing themselves and in helping them with their works. They engage themselves in organizations that welcomes them, learn a hobby, hone their talents and skills, and be recognized as they are and not because of their disability. They try to view the world differently and acknowledge themselves as normal people and believe that they can do what normal people do and even do better than them. The support that they get from their families and friends made them stronger and this strengthens their egos to pursue what they have started. They also view education as education for all. Regardless of their disability, they were able to go at par with other students. They have an innate motivation of building a stronger self-esteem that does not immediately drops down whenever a difficulty is encountered since they are already aware of their limitation and they had already prepared themselves for such situation. A combination of right attitude, favorable environment, and proper technology will lead VI students to success. 


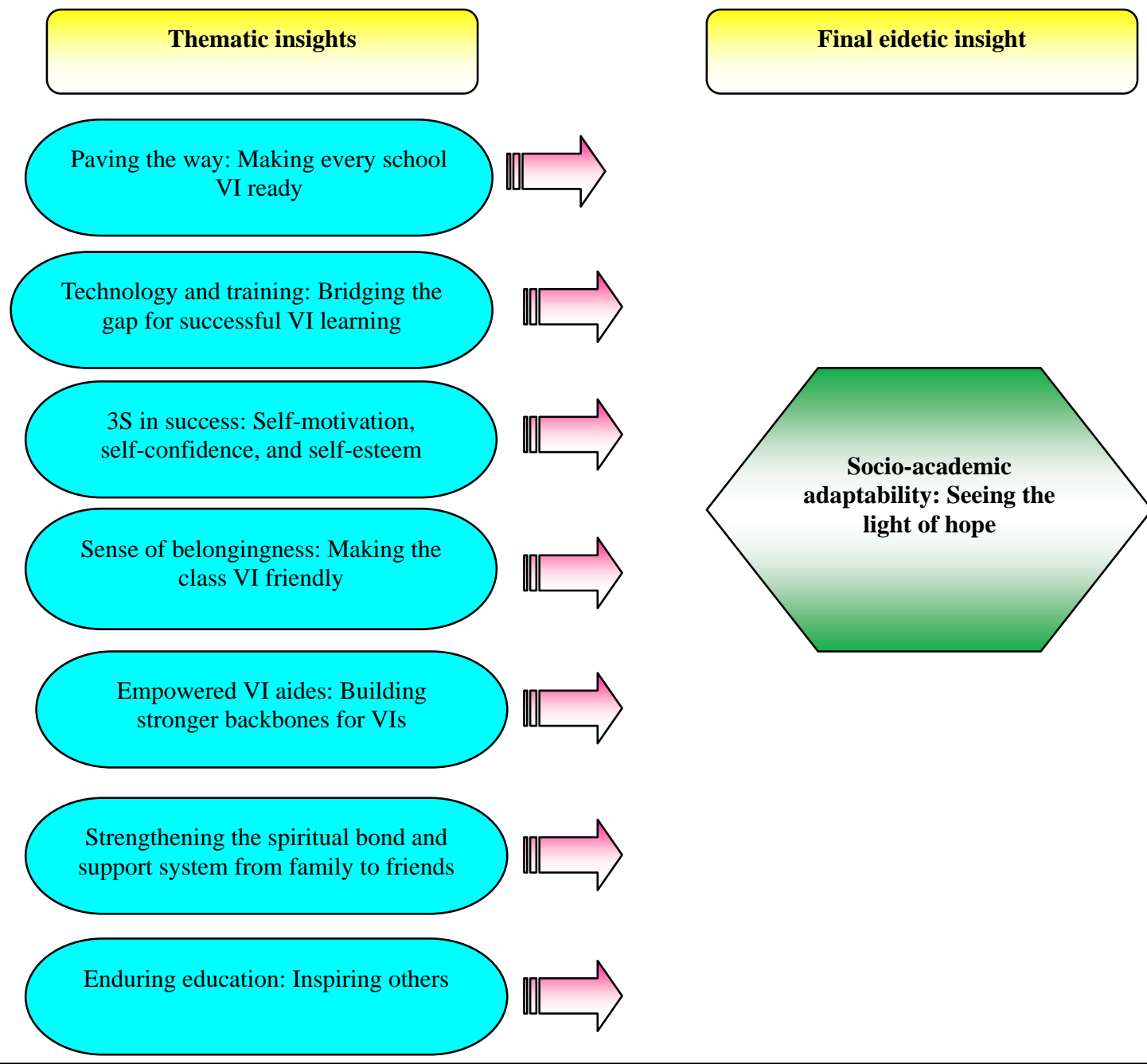

Figure 3. Concept map illustrating the themes of the study and its relation to the final eidetic insight.

\section{Recommendations}

The following are the recommendations based on the findings of the study:

1. Schools should develop facilities that can accommodate PWD especially VI students. In this same manner, they should prepare teachers with proper training in handling and teaching VI students in the classroom especially when these kinds of students are blended together with the mainstream class;

2. There should be an agency that trains aides or helper of VI students, so that there is an assurance that the aides or helper can maximize their potential to help the VI students in different aspects;

3. Schools should be equipped technologies that help VI students and make their teachers capable of using them to promote learning both for mainstream and VI students;

4. Schools should conduct seminars and orientations that promote protection and respect for VI students, so that they will know how to communicate and establish harmonious relationships among them.

5. School should create organizations that welcomes and strengthen VI students. 


\section{References}

Bennett, S., \& Gallagher, T. (2013). High school students with intellectual disabilities in the school and workplace: Multiple perspectives on inclusion. Canadian Journal of Education, 36, 96-124.

Batu, S., Bilgin, A., Oksal, A., \& Sadioglu, O. (2013). Problems, expectation, and suggestions of elementary teachers regarding inclusion. Educational Sciences, Theories and Practices, 13, 1760-1765. doi: 10.12738/estp.2013.3.1546

Celeste, M., \& Grum, D. K. (2010). Social integration of children with visual impairment: A developmental model. Elementary Education Online, 9(1), 11-22.

Costley, K. (2013). Ongoing professional development: The prerequisite for and continuation of successful inclusion meeting the academy needs of special students in public schools. Inclusion Professional Development, 1, 1-9. doi: 10.1027/1015-9040.3.3.207

Creswell, J. W. (2013). Qualitative inquiry and research design: Choosing among five approaches (3rd ed.). Thousand Oaks, CA: SAGE.

Creswell, J. W. (2014). Research design: Qualitative, quantitative and mixed methods approaches (4th ed.). Lincoln: Sage Publications.

Creswell, J. W., \& Miller, D. L. (2000). Determining validity in qualitative inquiry. Theory into Practice, 39, 124-130.

Gibbs, G. R. (2007). Thematic coding and categorizing, analyzing qualitative data. London: SAGE Publication Ltd.

Gresham, F. M. (1981). Social skills training with handicapped children: A review. Review of Educational Research, 51(1), 139-176. https://doi.org/10.3102/00346543051001139

Hatch, J. A. (2002). Doing qualitative research in education setting. Albany: SUNNY Press.

Hatlen, P. H., \& Curry, S. A. (1988). Meeting the unique educational needs of visually impaired pupils through appropriate placement. Journal of Visual Impairment \& Blindness, 82(10), 417-424.

Jordan, J. (2015). Satisfaction of students with visual impairment with different school settings. Educational Specialist, 10. Retrieved from https://commons.lib.jmu.edu/edspec201019/10

Kamenopoulou, L. (2012). A study on the inclusion of deaf blind young people in the mainstream schools: Key findings and implications for research and practice. British Journal of Special Education, 39, 137-145. doi: 10.1111/j.1467-8578.2012.00546.x

Kekelis, L. S., \& Sacks, S. Z. (1988). Mainstreaming visually impaired children into regular education programs: The effects of visual impairment on children's social interactions with peers. In S. Z. Sacks, L. S. Kekelis, and R. J. Gaylord-Ross (Eds.), The development of social skills by visually impaired children (pp. 59-82). San Francisco: San Francisco State University.

Lindsay, S., \& McPherson, A. (2012). Experiences of social exclusion and bullying at school satisfaction of students with visual impairment within different school settings 28 among children and youth with cerebral palsy. Disability and Rehabilitation, 34, 101-109. doi: 10.3109/09638288.2011.587086

Marshall, C., \& Rossman, G. B. (2011). Designing qualitative research (5th ed.). Thousand Oaks, CA: SAGE.

Mason, J. (2002). Qualitative researching. London: SAGE Publication Ltd. Retrieved from http://www.sxf.uevora.pt/wp-content/uploads/2013/03/Mason_2002.pdf

Mishra, V., \& Singh, A. (2012). A comparative study of self-concept and confidence of sighted and visually impaired children. EXCEL International Journal of Multidisciplinary Management Studies, 2(2), 148-157.

Moustakas, C. (1994). Phenomenological research methods. Thousand Oaks, CA: SAGE.

Porter, J., \& Lacey, P. (2008). Safe-guarding the needs of children with a visual impairment in non-vi special schools. British Journal of Visual Impairment, 26(1), 50-62.

Rathbun, A. H., \& West, J. (2003). Young children's access to computers in the home and at school in 1999 and 2000 (NCES 2003-036). Washington, DC: U.S. Department of Education, National Center for Education Statistics.

Rossman, G. B., \& Rallis, S. F. (2012). Learning in the field an introduction to qualitative research (3rd ed.). Sage: Los Angeles.

Sacks, S. Z., \& Wolffe, K. E. (2006). Teaching social skills to students with visual impairment: From theory to practice. New York: AFB Press, American Foundation for the Blind.

Shapiro, J. P. (1993). No pity. New York: Times Books, Random House.

Tavares, W. (2011). An evaluation of the kids are Kids disability awareness program: Increasing social inclusion among children with physical disabilities. Journal of Social Work in Disability and Rehabilitation, 10, 25-35. doi: 10.1080/1536710X 